\title{
Pengendali Modus Luncur Integral pada Posisi Panel Surya Penjejakan Dua Sumbu
}

\author{
Muhammad Imbarothur Mowaviq ${ }^{1}$; Tri Wahyu Oktaviana Putri ${ }^{2}$; Andi Junaidi ${ }^{3}$ \\ 1, 2, 3 Institut Teknologi PLN \\ ${ }^{1}$ mowaviq@itpln.ac.id
}

\begin{abstract}
Most solar panels in the world are placed in a fixed position, unchanging. To maximize the function of solar panels, we can use solar tracking that its orientation can follow the sunlight. The two-axis solar panel tracking system is driven by two DC motors which are controlled through Arduino Mega 2560. While the sensor used is the Light Dependent Resistor (LDR) sensor which has the working principle the higher the intensity of light that hits the sensor, the lower the sensor resistance. Position reading is done using a potentiometer. It is expected that the power generated by the solar panel is greater than the one-axis solar tracking system and the fixed-position solar panel by using two-axis solar tracking system. The system response is expected to be better and faster by using integrated sliding mode control. Integral Slide Mode Control is done in two stages. The first step is to make a sliding surface design that meets the design specifications. The second is the selection of control signals that will put the system on the sliding surface. From the test results, the application of sliding mode control can eliminate overshoot and improve response to 0,139s for $y$-axis and 0,412s for $x$ axis without overshoot. In the implementation, the settling time of y-axis is 0,23 s and the settling time of $x$-axis is 0,45 .
\end{abstract}

Keywords: Integral Sliding Mode Control, Solar Panel Position, Two-axis Tracking

\begin{abstract}
ABSTRAK
Kebanyakan panel surya di dunia diletakkan pada posisi yang tetap, tidak berubah-ubah. Untuk memaksimalkan fungsi dari panel surya, dapat menggunakan penjajak surya yang orientasinya bisa mengikuti cahaya matahari. Sistem penjajakan panel surya dua arah digerakkan oleh dua motor DC yang dikendalikan melalui Arduino Mega 2560. Sedangkan sensor yang digunakan adalah sensor Light Dependent Resistor (LDR) yang memiliki prinsip kerja semakin tinggi intensitas cahaya yang mengenai sensor, semakin rendah resistansi sensor. Pembacaan posisi dilakukan dengan menggunakan potensiometer. Dengan menggunakan sistem penjejakan surya dua arah diharapkan daya yang dibangkitkan oleh panel surya lebih besar dari pada sistem penjajakan surya satu arah dan panel surya posisi tetap. Dengan kendali modus luncur integral, diharapkan respon sistem menjadi lebih baik dan lebih cepat. Kendali Modus Luncur Integral dilakukan dengan dua tahap. Tahap pertama adalah membuat desain permukaan luncur yang memenuhi spesifikasi desain. Yang kedua pemilihan sinyal kontrol yang akan membuat sistem berada pada permukaan luncur Dari hasil pengujian yang diperoleh, dengan penerapan kendali modus luncur dapat dan memperbaiki respon menjadi 0,139s untuk sumbu y dan 0,412s untuk sumbu x tanpa overshoot. Pada implementasi didapatkan settling time untuk sumbu y sebesar 0,23s dan sumbu x sebesar 0,45s.
\end{abstract}

Kata kunci: Kendali Modus Luncur Integral, Posisi Panel Surya, Penjejakan Dua Sumbu 


\section{PENDAHULUAN}

Kebutuhan energi listrik yang selalu meningkat mesti dapat dipenuhi agar tidak terjadi kelangkaan energi [1]. Dua ancaman berupa menipisnya energi dan pemanasan global menghasilkan pengembangan sumber daya energi terbarukan di masyarakat. Energi surya adalah salah satu sumber energi terbarukan yang paling menjanjikan [2]. Sumber daya energi surya merupakan sumber daya yang ketersediaanya paling universal, yaitu dapat dijumpai di seluruh lokasi permukaan bumi. Dengan penerapan teknologi, energi surya dapat dimanfaatkan untuk menghasilkan energi dalam bentuk listrik atau energi panas. Berdasarkan data penyinaran matahari yang dihimpun di berbagai lokasi Indonesia menunjukkan sumber daya energi surya di Indonesia rata-rata $4.8 \mathrm{kWh} / \mathrm{m} 2$.hari dengan variasi bulanan sekitar 9\%[3]. Kapasitas terpasang PLTS di seluruh pulau di Indonesia terus mengalami peningkatan dari tahun 2005 sebesar 1,23 MWp, hingga tahun 2009 sebesar 13,50 MWp[4]

Kebanyakan panel surya di dunia diletakkan pada posisi yang tetap, tidak berubah-ubah. Untuk memaksimalkan fungsi dari panel surya, dapat menggunakan penjajak surya yang orientasinya bisa mengikuti cahaya matahari. Posisi panel surya yang digerakkan mengikuti pergerakan matahari ini dapat meningkatkan energi listrik yang dibangkitkan. Pada artikel yang ditulis oleh S. Ozcelik, H. Prakash, R. Chaloo [5], panel surya digerakkan dengan dua motor Direct Current (DC) 12 volts menggunakan pengendali Proporsional Integral Derivatif (PID). Amadi dan Gutierrez [6], pada penelitiannya menggunakan sensor Light Dependent Resistor (LDR), motor DC dan mikrokontroller. Dengan Dual Axis Tracking Systems (DATS), dihasilkan energi 31,4 \% energi lebih baik dari Single Axis Tracking System (SATS) dan 67,9\% lebih besar dari Fixed PV Panel System (FPPS). Pada artikel yang ditulis Mishra, dkk.[7] desain sistem penjejakan surya berbasis Arduino UNO yang mengarahkan pergerakan panel surya ke arah cahaya matahari yang maksimal.

Kendali Modus Luncur (KML) adalah Variable Structure Control (VSC) yang dikembangkan pertama kali pada tahun 1950 di Uni Soviet. VSC sendiri dikembangkan untuk berbagai sistem, termasuk sistem nonlinier, sistem Multi Input Multi Output (MIMO), model waktu diskrit, pada dimensi yang tak terbatas dari sebuah sistem [8]-[10]. Tahap pertama adalah membuat desain permukaan luncur yang memenuhi spesifikasi desain. Yang kedua pemilihan sinyal kontrol yang akan membuat sistem berada pada permukaan luncur [11].

Pentingnya kendali modus luncur tergantung pada akurasi tinggi, kesederhanaan implementasi dan ketahanan sehubungan dengan ketidakpastian parametrik model dan beberapa gangguan eksternal yang memengaruhi proses [12]. Skema kendali modus luncur integral, dapat mencapai kinerja kontrol yang lebih baik dibandingkan dengan skema kendali modus luncur konvensional [13]-[15]. Kendali modus luncur integral dengan umpan balik linier dapat melakukan penjejakan referensi masukan lebih cepat dibanding metode yang lain dengan kesalahan keadaan tunak yang sangat kecil. Dengan menerapkan kendali Kendali modus luncur integral, diharapkan dapat diperoleh respon sistem yang lebih baik dan dapat diperoleh pembangkitan energi listrik yang lebih baik.

\section{METODE/PERANCANGAN PENELITIAN}

\subsection{Perancangan Sistem}

Gambar desain rangka sistem penjejakan surya dua sumbu dapat dilihat pada Gambar 1 . Rangka sistem penjajakan surya dua sumbu dibuat dengan bahan yang ringan agar kinerja motor tidak terlalu berat, dalam penelitian ini menggunakan bahan alumunium. Selain panel surya, perangkat utama yang melekat pada rangka adalah dua buah motor penggerak. 


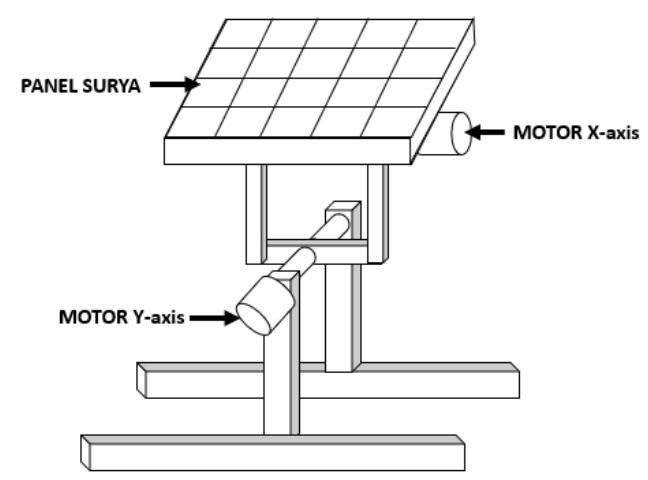

Gambar 1. Desain Rangka Sistem Penjajakan Surya

Sementara, untuk desain rangkaian elektrik dapat dilihat pada Gambar 2. Mikrokontroler yang digunakan adalah Arduino Mega 2560, di mana jumlah pin yang dimiliki lebih banyak dari versi Uno R3. Sensor yang digunakan adalah empat sensor LDR untuk mendeteksi cahaya matahari dan dua potensiometer untuk mendeteksi posisi sudut motor. Driver motor menggunakan tipe 1293n untuk mengatur dua buah motor DC. Ditambah dua motor DC yang sudah tertanam gear box. Sumber tegangan sebesar $12 \mathrm{~V}$ yang didapat baik dari baterai atau power supply menjadi sumber tegangan untuk Arduino Mega 2560 dan motor DC yang dihubungkan dengan driver motor 1298n. Untuk keterangan pin Arduino dapat dilihat pada Tabel 1.

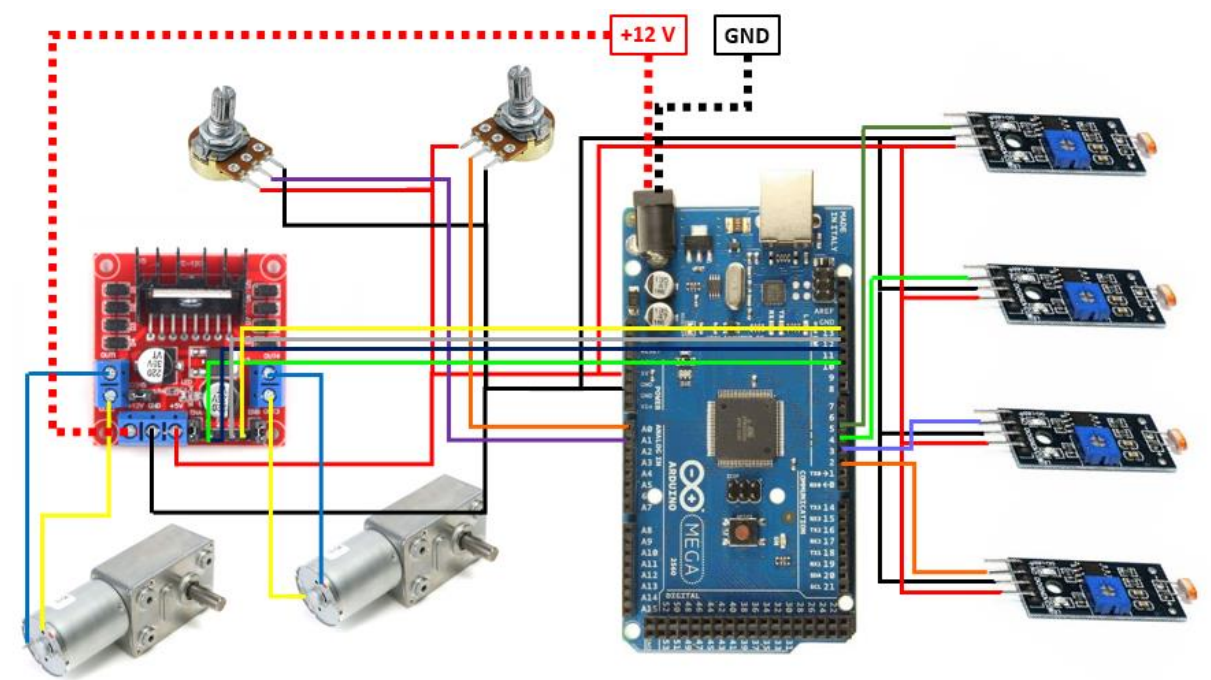

Gambar 2. Desain Rangkaian Elektrik

Tabel 1. Keterangan Pin Arduino Mega 2560

\begin{tabular}{|l|l|l|l|}
\hline Pin Arduino & Pin Komponen & Pin Arduino & Pin Komponen \\
\hline 2 & D0 LDR1 & A1 & Potensiometer 2 \\
\hline 3 & D0 LDR2 & 10 & IN1 driver 1293n \\
\hline 4 & D0LDR3 & 11 & IN2 driver 1293n \\
\hline 5 & D0 LDR4 & 12 & IN3 driver 1293n \\
\hline A0 & Potensiometer 1 & 13 & IN4 driver 1293n \\
\hline
\end{tabular}




\subsection{Perancangan Perangkat Lunak}

Dalam perancangan perangkat lunak, terlebih dahulu didesain diagram alir program seperti Gambar 3. Gambar tersebut menjelaskan tentang diagram alir program untuk pergerakan sumbu-X dan sama persis untuk sumbu-y

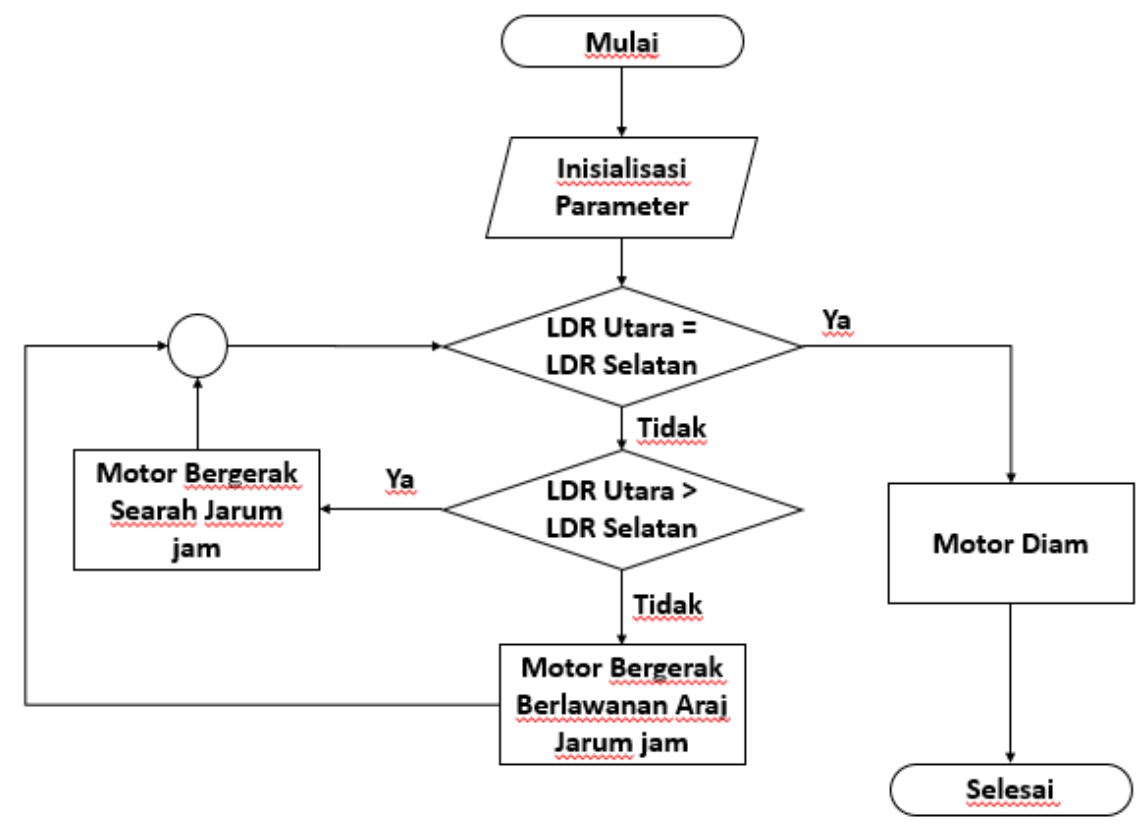

Gambar 3. Diagram Alir Sistem Penjajakan Surya Sumbu-x

\subsection{Pemodelan dan Identifikasi Sistem}

Desain kendali Kendali modus luncur integral diawali dengan melakukan pemodelan sistem terlebih dahulu. Pada pemodelan sistem, peneliti menggunakan identification tool MATLAB dengan lebih dahulu mendapatkan data masukan dan luaran dari sistem lup terbuka. Diagram blok pengambilan data lup terbuka dapat dilihat pada Gambar 4. Potensiometer digunakan sebagai sensor sudut.

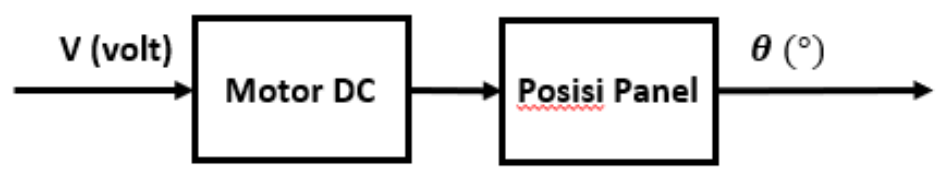

Gambar 4. Diagram Blok Pemodelan

Dari data masukan dan keluaran yang sudah didapatkan kemudian diolah menggunakan identification tool MATLAB. Waktu cuplik yang digunakan adalah 0,015 detik. Fungsi alih yang dipilih adalah orde dua tanpa zero.

Setelah dilakukan pemodelan didapatkan fungsi alih orde dua sebagai berikut:

$$
\begin{aligned}
& \frac{C_{x}(s)}{R_{x}(s)}=\frac{99460}{s^{2}+11610 s+1716} \\
& \frac{C_{y}(s)}{R_{y}(s)}=\frac{47060}{s^{2}+6105 s+902.3}
\end{aligned}
$$


PETIR: Jurnal Pengkajian dan Penerapan Teknik Informatika

Vol. 13, No. 2, September 2020, P-ISSN 1978-9262, E-ISSN 2655-5018

DOI: https://doi.org/10.33322/petir.v13i2.1056

Adapun respon unit step dari fungsi alih tersebut dapat dilihat pada Gambar 5. Pada Gambar 5.a. respon unit step fungsi alih terbuka menunjukkan amplitude yang dihasilkan sumbu $\mathrm{x}$ lebih besar dari pada sumbu y. Hal ini disebabkan karena sumbu y memiliki beban yang lebih berat. Pada fungsi alih lup tertutup untuk sumbu x settling time sebesar 0.4487 dan pada sumbu y sebesar 0.4975.
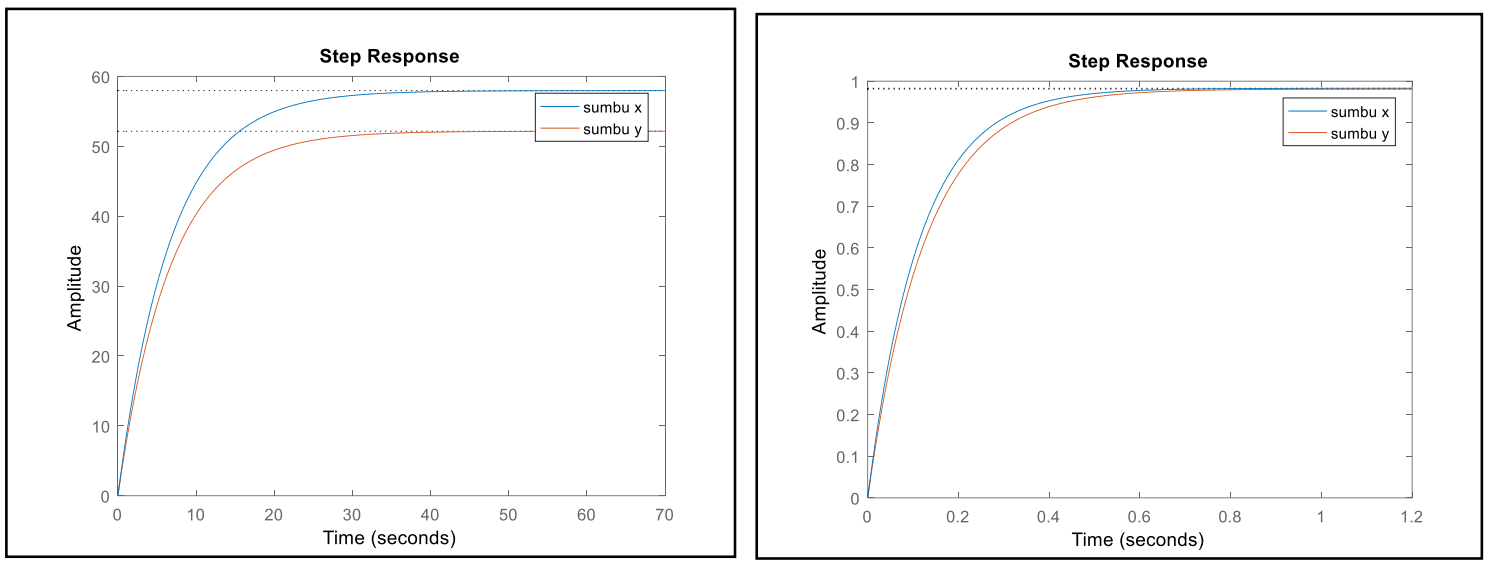

Gambar 5. (a) Respon unit step fungsi alih terbuka (b) Respon unit step lup tertutup

\subsection{Kendali Modus Luncur Integral}

Sistem yang digunakan adalah orde dua dalam bentuk

$$
\ddot{x}=a_{1} \dot{x}+a_{2} x+b u
$$

dengan persamaan kendali modus luncur integral

$$
u=\frac{-\left(a_{2} x+\left(a_{1}+2 \lambda\right) \dot{x}+\lambda^{2}\left(x-x_{d}\right)\right)}{b}-K \operatorname{sign}(s)
$$

Adapun diagram blok kendali modus luncur integral untuk sisitem orde dua dapat dilihat pada Gambar 6.

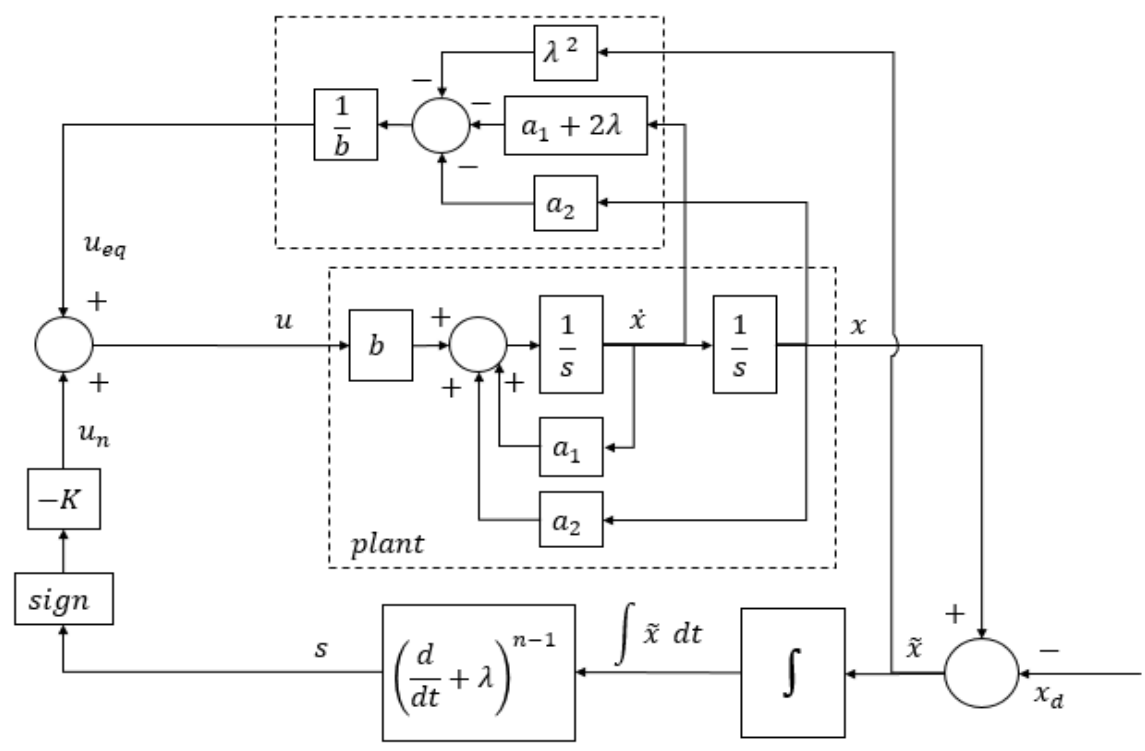

Gambar 6. Blok Diagram Kendali Modus Luncur Integral 
Berdasarkan pada persaman (1) dan (3) maka fungsi alih diubah menjadi

$$
\ddot{x}_{x}=11610 \dot{x}_{x}+1716 x_{x}+99460 u_{x}
$$

diperoleh nilai

$$
a_{x 1}=11610, \quad a_{x 2}=1716, \quad \operatorname{dan} b_{x}=99460
$$

Berdasarkan persamaan (6) dan (4), maka diperoleh

$$
u_{x}=\frac{-\left(1716 x_{x}+(11610+2 \lambda) \dot{x}_{x}+\lambda^{2}\left(x_{x}-x_{x d}\right)\right)}{99460}-K \operatorname{sign}(s)
$$

Kemudian untuk sumbu y, berdasarkan pada persaman (2) dan (3) maka fungsi alih diubah menjadi

$$
\ddot{x}_{y}=6105 \dot{x}_{y}+902.3 x_{y}+47060 u_{y}
$$

diperoleh nilai

$$
a_{y 2}=6105, \quad a_{y 2}=902.3, \quad \operatorname{dan} b_{x}=47060
$$

Berdasarkan persamaan (5) dan (3), maka diperoleh

$$
u_{y}=\frac{-\left(902.3 x_{x}+(6105+2 \lambda) \dot{x}_{x}+\lambda^{2}\left(x_{y}-x_{y d}\right)\right)}{47060}-K \operatorname{sign}(s)(10)
$$

Selanjutnya, dengan melakukan simulasi menggunakan Simulink, dapat kita peroleh nilai $\lambda$ dan $K$ yang sesuai. Pemilihan dilakukan dengan melihat karakteristik nilai $\lambda$ yang besar dan kecil. Pada penelitian ini didapatkan dengan nilai $\lambda$ yang cukup besar diperoleh hasil yang lebih baik. Adapun diagram blok simulasi dapat dilihat pada Gambar 7. Di mana terdapat saturasi sinyal kendali sebesar $\pm 11,5 \mathrm{~V}$ yang mana itu merupakan keluaran maksimal driver L298n.

$$
K_{x_{s}}=2 \lambda, K_{x_{u e q}}=\frac{-\lambda^{2}}{b}, K_{i_{s}}=\lambda^{2}, \text { dan } K_{u_{e q}}=\frac{a-2 \lambda}{b}
$$

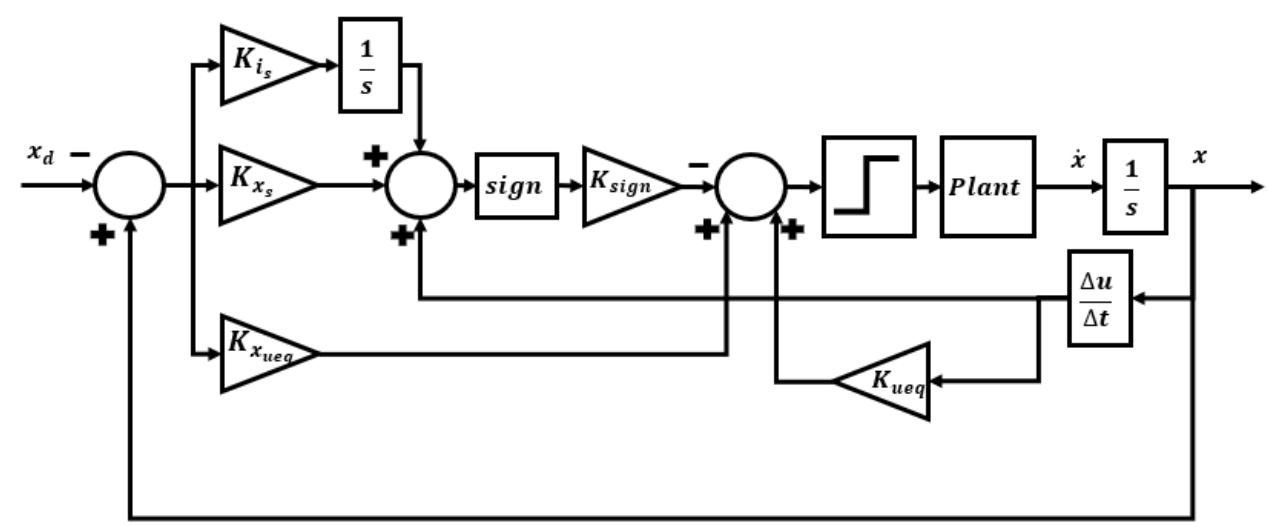

Gambar 7. Diagram Blok Simulasi 
PETIR: Jurnal Pengkajian dan Penerapan Teknik Informatika

Vol. 13, No. 2, September 2020, P-ISSN 1978-9262, E-ISSN 2655-5018

DOI: https://doi.org/10.33322/petir.v13i2.1056

\section{HASIL DAN PEMBAHASAN}

Pemilihan parameter kendali modus luncur integral dapat dilihat pada Tabel 1. Pemilihan $\lambda$ mempertimbangkan nilai $K_{u_{e q}}$ agar bernilai negatif. Berdasarkan uji simulasi menggunakan Simulink MATLAB maka didapatkan hasil pada Gambar 8.

Tabel 2. Parameter Kendali

\begin{tabular}{|c|c|c|}
\hline Parameter & Sumbu x & Sumbu y \\
\hline$\lambda$ & 8000 & 3500 \\
\hline$K_{x_{s}}$ & 16000 & 7000 \\
\hline$K_{x_{u e q}}$ & $-643,475$ & $-260,306$ \\
\hline$K_{i_{s}}$ & 64000000 & 12250000 \\
\hline$K_{u_{e q}}$ & $-0,044$ & $-0,019$ \\
\hline$K_{\text {sign }}$ & 1 & 1 \\
\hline
\end{tabular}

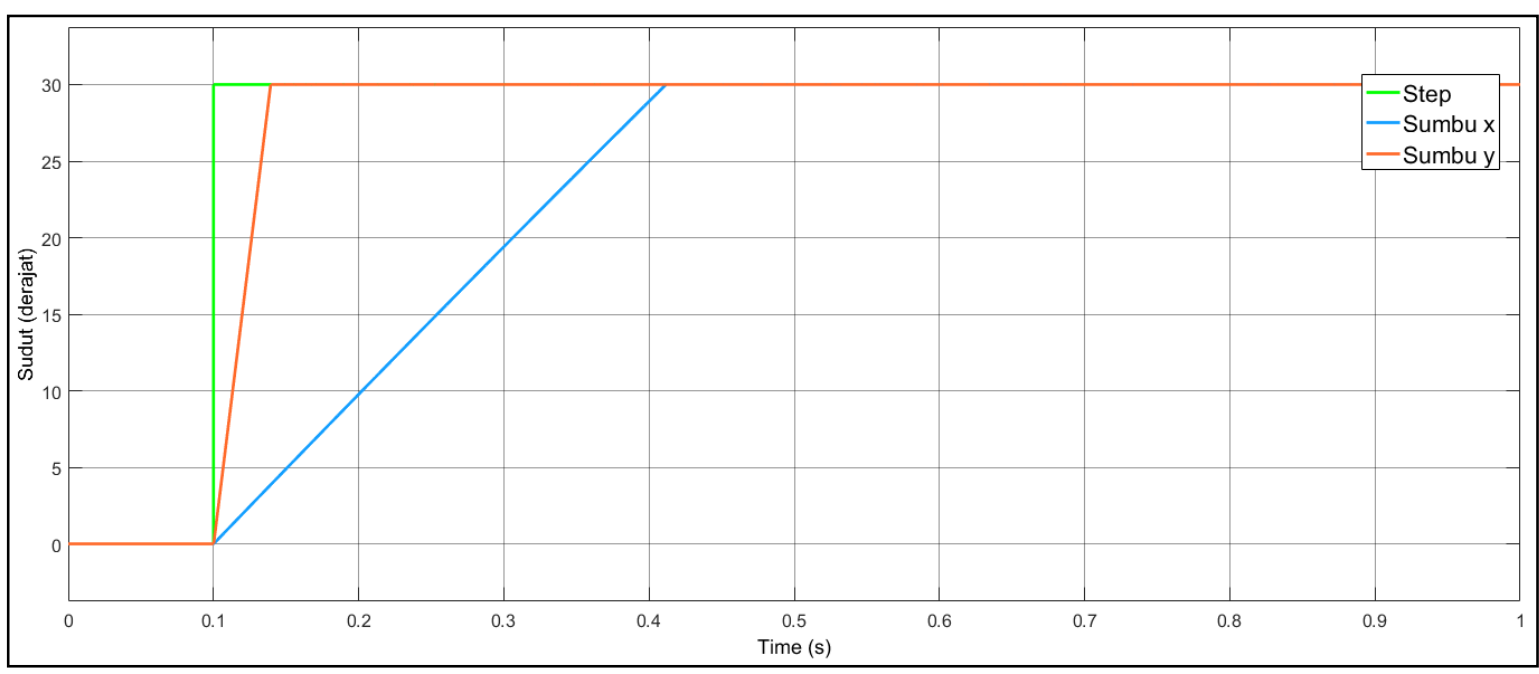

Gambar 8. Step Response Kendali Modus Luncur Integral

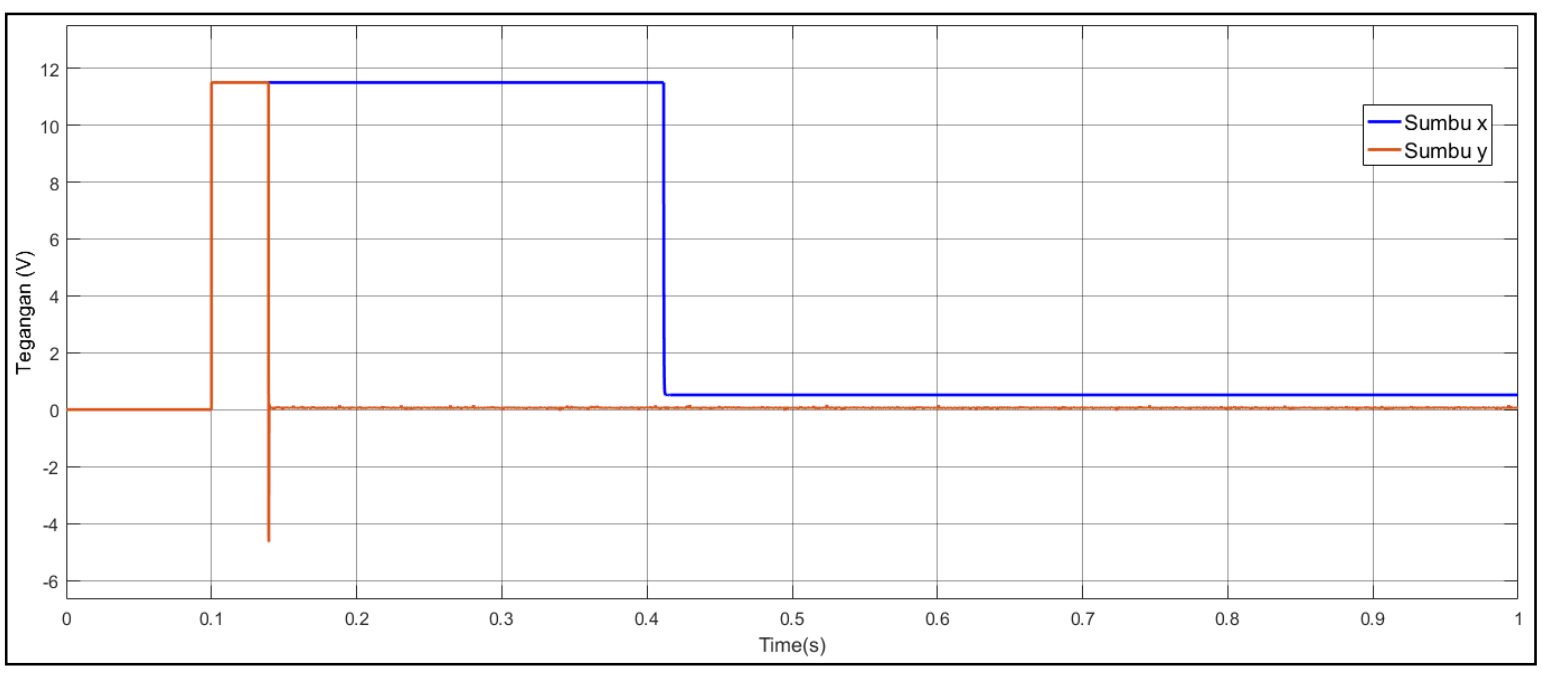

Gambar 9. Sinyal Kendali Modus Luncur Integral 
PETIR: Jurnal Pengkajian dan Penerapan Teknik Informatika

Vol. 13, No. 2, September 2020, P-ISSN 1978-9262, E-ISSN 2655-5018

DOI: https://doi.org/10.33322/petir.v13i2.1056

Dari hasil yang ditampilkan pada Gambar 8, diperoleh settling time untuk sumbu y sebesar 0,139 s dan sumbu x sebesar 0,412 s. Pada simulasi didapatkan hasil dengan respon yang lebih cepat dan tanpa overshoot. Sedangkan sinyal kendali dapat dilihat pada Gambar 9. Sementara untuk hasil implementasi Kendali modus luncur dapat dilihat pada Gambar 10 dan sinyal kendalinya pada Gambar 11.

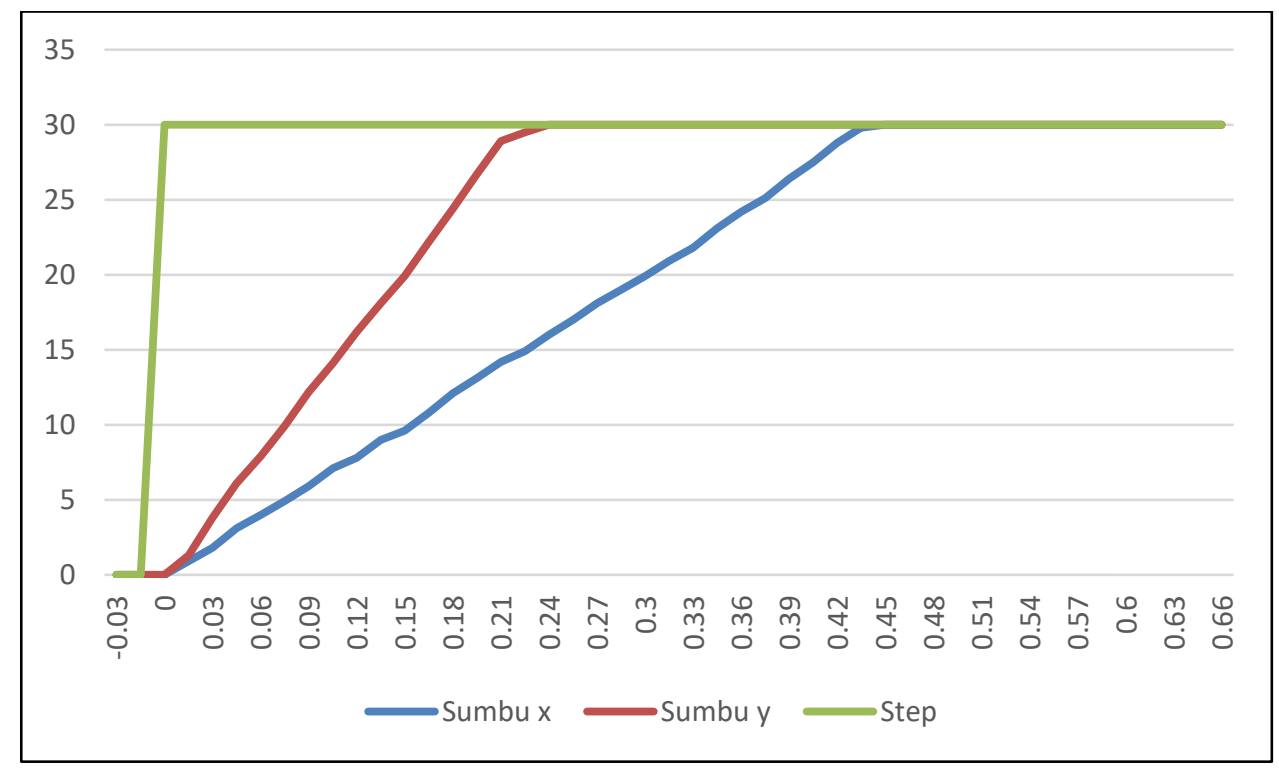

Gambar 10. Implementasi Kendali Modus Luncur Integral

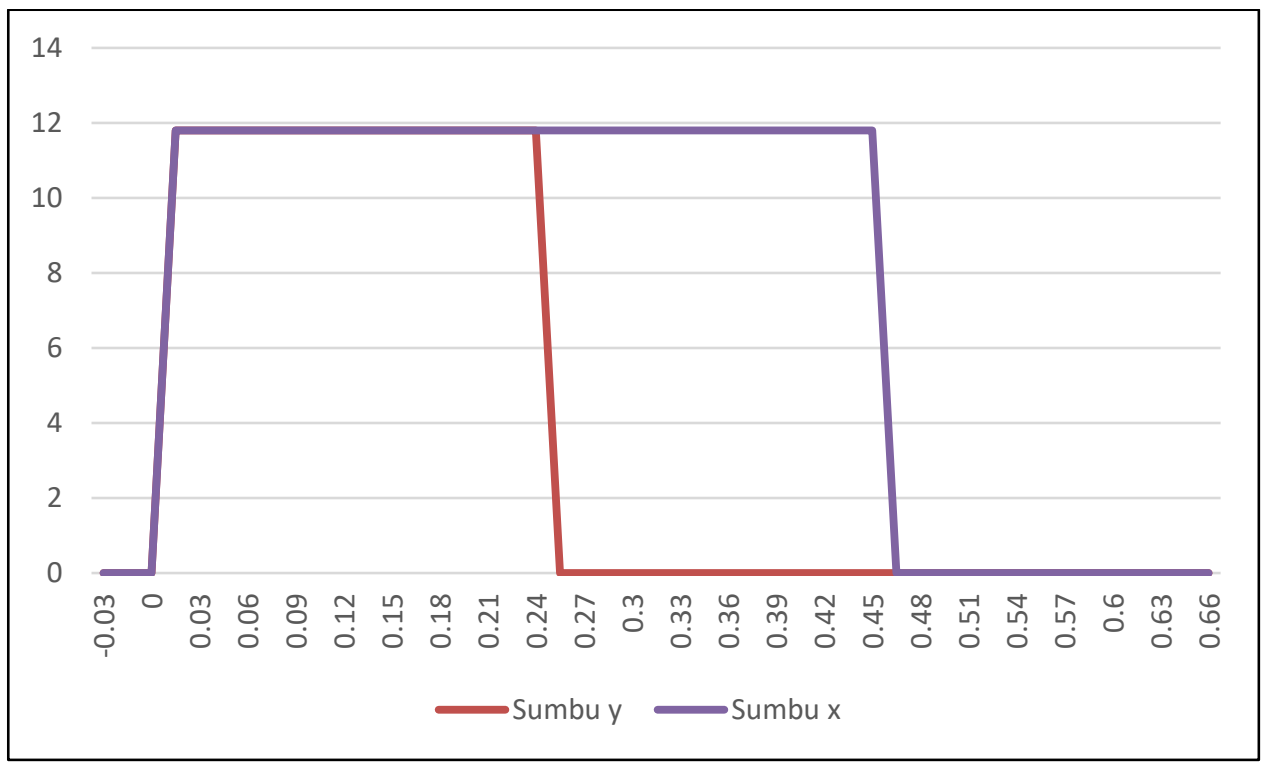

Gambar 11. Implementasi Sinyal Kendali Modus Luncur Integral

Dari hasil implementasi kendali modus luncur pada sistem yand ditunjukkan oleh Gambar 10, diperoleh settling time untuk sumbu y sebesar $0,23 \mathrm{~s}$ dan sumbu x sebesar $0,45 \mathrm{~s}$. Pada implementasi seperti halnya simulasi didapatkan hasil dengan respon yang lebih cepat dan tanpa overshoot. 


\section{KESIMPULAN DAN SARAN}

Dari hasil yang diperoleh, didapatkan kesimpulan bahwa dengan mengimplementasikan kendali modus luncur integral, performansi penjejakan surya menjadi lebih baik. Berdasarkan pengujian dengan masukan unit step respon berubah menjadi 0,139 s dan sumbu x sebesar $0,412 \mathrm{~s}$. Pada implementasi didapatkan settling time untuk sumbu y sebesar $0,23 \mathrm{~s}$ dan sumbu x sebesar $0,45 \mathrm{~s}$. Hal ini menunjukkan bahwa kendali modus luncur integral dapat memperbaiki sistem dengan nonlinearitas berupa saturasi pada masukan. Untuk penelitian selanjutnya perlu dilakukan penelitian terkait perbandingan daya keluaran panel surya antara satu sumbu dan posisi tetap dalam rentang waktu yang lebih lama.

\section{UCAPAN TERIMAKASIH}

Penulis mengucapkan terima kasih kepada Institut Teknologi PLN yang telah memberi dukungan yang membantu pelaksanaan penelitian dan atau penulisan artikel.

\section{DAFTAR PUSTAKA}

[1] M. I. Mowaviq, A. Junaidi, and S. Purwanto, "Lantai Permanen Energi Listrik Menggunakan Piezoelektrik," Energi \& Kelistrikan, vol. 10, no. 2, pp. 112-118, 2019.

[2] J. M. Wang and C. L. Lu, "Design and implementation of a sun tracker with a dual-axis single motor for an optical sensor-based photovoltaic system," Sensors (Switzerland), vol. 13, no. 3, pp. 3157-3168, Mar. 2013.

[3] Pusat Data dan Informasi Energi Sumber Daya Mineral, "Indonesia Energy Outlook 2010," 2010.

[4] C. Hilman and A. Musyafa, "Rancang Bangun Dual-Axis PV Solar Tracker System Menggunakan Interval Type-2 Fuzzy Logic Controller," in Seminar Nasional Pascasarjana XIV, 2014.

[5] S. Ozcelik, H. Prakash, and R. Challoo, "Two-axis solar tracker analysis and control for maximum power generation," in Procedia Computer Science, 2011, vol. 6, pp. 457-462.

[6] H. N. Amadi and S. Gutierrez, "Design and Performance Evaluation of a Dual-Axis Solar Tracking System for Rural Applications,” Eur. J. Electr. Eng. Comput. Sci., vol. 3, no. 1, Jan. 2019.

[7] J. Mishra, R. Thakur, and A. Deep, "Arduino based Dual Axis Smart Solar Tracker," Int. J. Adv. Eng. Manag. Sci., vol. 3, no. 5, pp. 532-535, 2017.

[8] M. I. Mowaviq and A. S. Rohman, "Embedded position control of permanent magnet synchronous motor using sliding mode control," in 2018 International Conference on Signals and Systems (ICSigSys), 2018, pp. 162-165.

[9] R. A. Decarlo, S. H. Zak, and G. P. Matthews, "Variable Structure Control of Nonlinear Multivariate Systems: A Tutorial,” Proc. IEEE, vol. 76, no. 3, pp. 212-232, 1988.

[10] M. Nishanthi and A. k Sunny, "Sliding Mode Control for the Stability Analysis of a Variable Speed Wind Turbine,” Int. J. Eng. Trends Technol., vol. 33, no. 6, pp. 277-282, 2016.

[11] V. I. Utkin, "Sliding Mode Control Design Principles and Applications to Electric Drives," IEEE Trans. Ind. Electron., vol. 40, no. 1, pp. 23-36, 1993.

[12] D. Fereka, M. Zerikat, and A. Belaidi, "MRAS Sensorless Speed Control of an Induction Motor Drive based on Fuzzy Sliding Mode Control," in 2018 7th International Conference on Systems and Control, ICSC 2018, 2018, pp. 230-236. 
PETIR: Jurnal Pengkajian dan Penerapan Teknik Informatika

Vol. 13, No. 2, September 2020, P-ISSN 1978-9262, E-ISSN 2655-5018 DOI: https://doi.org/10.33322/petir.v13i2.1056

[13] S. Chen and C. Kuo, "Design and implementation of double-integral sliding-mode controller for brushless direct current motor speed control," Adv. Mech. Eng., vol. 9, no. 1, pp. 1-9, 2017.

[14] F. L. S. C. M. Huang, "Intelligent double integral sliding-mode control for five-degree-offreedom active magnetic bearing system," IET Control Theory Appl., vol. 5, no. 11, pp. 12871303, 2011.

[15] Y. Li, B. Yang, T. Zheng, Y. Li, M. Cui, and S. Peeta, "Extended-State-Observer-Based Double-Loop Integral Sliding-Mode Control of Electronic Throttle Valve," IEEE Trans. Intell. Transp. Syst., pp. 1-10, 2015. 